Featured Essay

\title{
Knowledge as Addiction: A Comparative Analysis
}

Hans-Georg Moeller

I

1 1 11 men by nature desire to know" - this is the famous first $\triangle$ sentence of Aristotle's Meaphysics It is interesting to note how

1 knowledge, at least since Aristotle, could be understood as a desire, as a mental craving, so to speak. When understood as a desire, knowledge necessarily goes along with a certain absence, a lack. Those who crave for knowledge are not yet fully in its possession, they are still on the search.

If humans pursue a cognitive desire that is not wholly fulfilled- since there is something yet unknown, something yet to be discovered-are they then not pitiful beings? Aristotle did obviously not draw this conclusion. Unlike bodily desires, the soul's desire for knowledge could be regarded as a noble one, and rather than being a weakness, it could be an indicator of human dignity and power. The human strive for knowledge serves to distinguish this species from animals that do not, at least apparently, have such a desire. Aristotle praises the intellectual curiosity that was, for him, so significant for being human. Human rational desires can be distinguished from the merely physical drives of animals. Later humanist ideals accordingly view life as a process of personal transformation and growth through learning and the continuous acquiring of knowledge- or a process of Bildungto use a German term that stands for an enlightenment ideal of human cultivation. In the humanist tradition, the desire for knowledge was highly cherished-even if it was insatiable.

If one leaves the humanist tradition, however, one can encounter evaluations of knowledge that are quite different. One such instance is D aoist philosophy. Here, the permanent need that goes along with the desire for more and more knowledge is seen as substantially similar to the never ending state of want that goes along with physical cravings. Accordingly, the striving for knowledge was equated with incessant bodily desires-and could thus appear as a kind of addiction. 


\section{KNOWLEDGE AS ADDICTION}

II

The negative attitude towards knowledge in Daoism is particularly obvious in the Laozi (or Daodging. ${ }^{1}$ Chapter 3 says:

When the worthies are not promoted, then this will make the people not contending.

When the goods that are difficult to obtain are not esteemed, robbers.

then this will make the people not become

When that which is desirable is not displayed, then this will make the people not disorderly.

Therefore the ordering of the sage is such:

He empties their hearts;

he fills their bellies.

He weakens their wishes; he strengthens their bones.

Persistently he makes the people have no knowledge and no desires.

It is a Confucian doctrine to promote the worthy and wise in order to have the most virtuous people in the government. From a D aoist perspective such a practice will only lead to conflict among the people. They will develop a desire for political powers and thus there will be a competitive atmosphere and the social harmony will be poisoned. Similarly, the display of scarce luxury goods will unnecessarily and artificially create needs. Obviously, the Daoists neither cherished political competition nor an economy based on demand. Politically and economically, what was envisioned was a state of contentment rather than one of contention. The chapter advises the sage ruler, on the one hand, to provide for basic needs, particularly for sufficient food, and, on the other hand, to prevent any kind of craving for more than is needed. Satiation and satisfaction are reached when a mindset of yearning is avoided. If such a mindset cannot be avoided, this will lead to a state of addiction and strife. The people's desire for consumption would be awakened and there would be a permanent struggle among all.

Interestingly enough, the yearning that the Daoist sage ruler is supposed to prevent explicitly includes the desire for intellectual "properties" such as knowledge. Addiction is not limited to material goods and social

${ }^{1}$ I have used my own translation in citing passages from the Daodging See HansG eorg Moeller ed. and trans., Daodging(Laozi) (Chicago: O pen Court, 2007). 
H. MOELLER 3

power; it also extends to the strife for knowledge. Just as material indulgence may lead to a state of a continuous want for more and better goods, intellectual indulgence might create a hunger for more information. Peace of mind among the people - and a peaceful society - can only be attained if the arising of both physical and mental yearnings is quelled.

In a similar vein, chapter 57 states:

If the people have many sharp tools, disorder.

the state and the families will increasingly be in

If men have a lot of knowledge and sophistication, there will increasingly appear weird things.

Very much opposed to our "post-enlightenment" vision of the informed citizen, the spread of knowledge among people was not seen as socially beneficial by the early D aoists. In a simple, agrarian life, what counted was the stability and peacefulness of society. People were supposed to spend their days by performing their respective tasks and not to be encouraged to introduce novelties. The Laozi promotes an ancient Chinese version of a "Luddite" position. From its perspective, innovations produce more social harm than practical benefit. An increase in knowledge and sophistication will only lead to more discontent and friction. It will make people cunning and scheming and depart from natural simplicity. Chapter 18 thus warns:

When knowledge and smartness come out, then there is great falsity.

And chapter 19 continues:

Abandon sageliness and discard knowledge, and the people will benefit be a hundredfold.

Chapter 71 summarizes this negative attitude towards knowledge:

To know not-knowingthis is the highest.

To not know not-knowing this is a blemish.

Still, if one reads these lines carefully, one discovers a paradox - and the use of paradoxes is nothing uncommon in Daoism and particularly not in the Laori. Chapter 71 explicitly advises to knownot-knowing. So, after all, there seems to be at least one thing one is supposed to know, there remains one kind of negative knowledge that the sage, or, in the political context of the Laczi, the sage ruler is supposed to acquire. Similarly ambiguous is chapter 65: 


\section{KNOWLEDGE AS ADDICTION}

Those who in antiquity practiced the $\mathrm{D}$ ao did not do this by enlightening the people, but by keeping them dull.

Well, when people are difficult to govern the reason is that they are knowing.

Thus:

To master (know) the state by making it knowledgeable is to commit a crime on the state.

To master (know) the state by making it non-

knowledgable is a virtue to the state.

Who constantly masters (knows) these two also finds the pattern.

To constantly master (know) the found pattern, this is called: dark virtue.

On the one hand, it is clear that the sage ruler's duty is to "keep people dull," to prevent them, for their own benefit, from becoming burdened with the insatiable desire for knowledge. But this technique of government is something that the sage himself has to know or to master- and the Chinese word for these two English terms is the same, namely zhi. The sage "masters" (zhi) the art of not-knowing (bu zhi). The ambiguous semantics of the word zhi in ancient Chinese has its parallel in modern English and in modern German. Ludwig Wittgenstein has remarked in his Philosophical Investigations (150)which, of course, was originally written in German:

The grammar of the word "to know" (wissen) is obviously closely related to the grammar of the words "can" (können) and "to be able to;" (imstande sein) but also closely related to that of the word "to understand." (verstehen) (To "master" ("beherrschen") a technique.)

To know something well can mean to master something perfectly. Sometimes we use the word "to know" in the sense of to know how rather than to know that. That kind of-less intellectual and more practical-knowing seems to be highly appreciated in the L aozi. The sage ruler keeps the people non-knowing and he remains so himself-but this not-knowing is at the same time a perfect mastery of the art of government. The sage ruler masters the art of not-knowing and thereby keeps the state in order. In this way, the paradoxical verses of chapter 47 make sense:

Not to go out of the doorto know the world 


\author{
Not to look out of the window- \\ to know the $\mathrm{D}$ ao of heaven. \\ The further one goes out, \\ the less one will know. \\ Therefore the sage \\ knows without going, \\ names without seeing, \\ completes without acting.
}

The sage ruler practices an abstinence of knowing-that and thereby, paradoxically enough, manages to reach the maximum in knowing-how. As in many instances this paradoxical logic may be explained with the help of an illustration that is found several times in the Laozi. The sage (ruler) is sometimes (for instance in chapters 55 and 10) compared with an infant. An infant has yet practically no knowing-that knowledge at all, but it has, from a D aoist point of view, perfect knowing-how knowledge. It lives without the expenditure of energy and "instinctively" knows what to do to survive. It eats and digests, it breathes and sleeps, etc. Without any reflection and without being taught, the infant does what needs to be done and inflicts no harm on itself or on others. A similar state of perfect mastery without knowledge is envisioned for the D aoist sage. Chapter 81 points out:

\title{
The one who knows is not erudite. \\ The one who is erudite does not know.
}

The Daoist sage knows like an infant, or like an animal, in a very nonAristotelian way. The sage does not venture out on a never-ending journey of intellectual discoveries, but remains at his place and masters the art of intellectual reduction-for the sake of perfecting his natural abilities and instincts. He prevents "positive" knowledge from interfering with what he can do "self-so" (ziran). Similarly, it is believed, the people in his state, the farming subjects, will not develop a desire for knowledge and will thus "instinctively" do what is right and what is in accord with the yearly cycle of the growth of their agricultural products. If one refrains from the seductions of knowledge one will be able to act in perfect harmony with what is naturally so. More knowledge only leads to more interference, to more "artificial" infringements on what is natural.

The negative/ positive knowledge of the Daoist sage, his mastery of not-knowing, is described in more concrete terms in a number of chapters. Chapter 55 states that he knows harmony and constancy, chapter 43 states that he knows the benefits of non-acting, and, perhaps most importantly, chapters 32,33 , and 44 state that he knows when to stop (zhi zhi) and when it is enough 
KNOWLEDGE AS ADDICTION

(zhi zu). It is particularly this last kind of "instinctive" knowledge that contrasts squarely with the Aristotelian view of the incessant human quest for knowledge. The non-addicted person "knows when to stop" and "knows when it is enough." The Daoist knowledge is a mastery of satisfaction. It prevents the insatiable desire for knowledge from emerging and thus creates a condition of permanent and perfect contentment and instinctive mastery and knowing-how.

III

Switching from ancient Daoism to our postmodern times, it can be said, from the perspective of social systems theory, ${ }^{2}$ that the production of knowledge is to a great extent performed by two different social systems, namely the sciences and the mass media. As opposed to the sciences, the mass media do not create specialized knowledge that is only known by a group of experts. The mass media create knowledge that is virtually known by all- and scientific knowledge has to be transformed into mass media knowledge to become widespread. When such terms as the "CO2-emissions" or "genetic engineering" become familiar then this is not because people have now begun to read scientific articles in great numbers, but because topics in which these terms play an important role have become mass media material so that they appear in newspapers, on television, in popular books, in films, and on websites. That all of us have some sort of idea what genetic engineering and the $\mathrm{CO} 2$ emissions are is not due to any scientific familiarity with these terms, but to our consumption of mass media communication about them.

The knowledge that the mass media create is quite different from the knowledge created in the sciences. Scientific knowledge is in-depth knowledge and it is, in the sciences, subject to continuous scrutiny. The sciences, particularly the natural sciences, consist largely of, to use Thomas Kuhn's term, "mop-up operations" in which scientific knowledge is proven to be right or wrong-or, more precisely, in which its way of being right or wrong is modified. ${ }^{3}$ "Normal science" consists in conducting experiments and publishing articles that either prove or disprove a certain hypothesis and add some more details to what is already known to be the case or not to be the case. The basic code of the scientific system is therefore correct/ false or right/ wrong.

This is not so in the mass media. The mass media do not waste time with such considerations, they do not conduct research in the strict sense-

\footnotetext{
2 I am following here Niklas Luhmann's version of social systems theory, particularly his two books DieWissenshaft der Gesdlschatt(Frankfurt/ Main: Suhrkamp, 1990) and TheReality of theMass Meda, trans. by Kathleen Cross (Stanford: Stanford University Press, 2000).

3 I am following here Thomas Kuhn's theory of the evolution of the sciences as depicted in his The Structure of Saientific Revdutions (Chicago: Chicago University Press, 1962). It should be noted that for both Kuhn and Luhmann the distinction right/ wrong in the sciences does not mean that "absolute" truths are discovered. What is "true" or "right" is always dependent on the discourse and changes continuously. It is, so to speak, a "social construct."
} 
they may report on research that is being done, but they do not engage in scientific research themselves- as just said, they literally do not have the time to do this. What the mass media do with respect to scientific knowledge is basically to transform it into a different kind of knowledge and into a different code. The mass media do not and cannot do research on the ozone layer or on genetic engineering, but they transform the scientific truths and falsities into information. Information, if compared to scientific truths or falsities, just gives you the facts- without an in-depth explanation. We know that $\mathrm{CO} 2$ emissions exist, but most of us do not really know what it exactly is; and we know that the genetic code exists, but we do not know what it really consists of. This, however, is not to say that the mass media merely present scientific knowledge in a shallow or superficial way. They do not restrict themselves to a mere representation of scientific facts. In order to transform scientific truths into information, the mass media have to add elements that make the scientific facts interesting. It is not interesting that $\mathrm{CO} 2$ emissions exist, but that they endanger the whole planet. It is not interesting that there is a genetic code, but that it can be manipulated. The scientific facts that occur in the mass media no longer resemble scientific facts in the scientific system; they rather resemble other news items or other entertainment topics. The code of the mass media is information/non-information and not truth/falsity. A fact has to be transformed into information in order to be communicated in the mass media system, and information goes along with what may be called a "spectacularization" or "narrativization" of facts. In the news, the information on the $\mathrm{CO} 2$ emissions is taken out of the context of the scientific discourse and is resettled into a story line within the news. We hear about who is trying to control them and which country does not, we hear about politicians and lawmakers who invest an interest in them, etc. Likewise, in the mass media genetic engineering can be integrated into the plot of a Hollywood movie or a best-selling novel. In the news, a film, or a novel, scientific knowledge is no longer scientific knowledge, it becomes information within a larger narrative and therefore it changes its form. The $\mathrm{CO} 2$ emissions that appear as information in the news and the genetic engineering that appears as information in an entertainment programme fulfill a completely different communicational function here than in the scientific system.

Another crucial difference between scientific communication and mass media communication is their respective temporality. What is a fact in the scientific system usually stays a fact for an extended period of time. Even though the mopping-up operations modify the facts constantly, the basic facts, or rather, in Kuhnian terms, the paradigm, remains stable- otherwise we could not be trained in a science. If the paradigm would shift on a daily basis, nobody would be able to keep up with these changes and there would be no community of scientists. Scientific discourse is based on the stability of at least some of its premises. When writing a scientific article or scientific books, one relies on a large number of facts that are accepted as scientific knowledge. A scientific book that would entirely consist of new knowledge would be 


\section{KNOWLEDGE AS ADDICTION}

unintelligible and could not connect to the existing discourse. It would not fit into the paradigm and would therefore be hardly acceptable as science at all.

This is, again, not so with information. Once it is uttered, information becomes non-information and needs to be replaced with new information. This is a decisive difference between the scientific and the mass media code. The scientific code does not immediately transform one side of the code into the other. A scientific truth that is uttered does not become by the very utterance a falsity. When you report something as news, however, it immediately loses its "newness." Today's news cannot repeat yesterday's news, news always have to be new. Very obvious examples for this mechanism are weather reports or sports coverage. Y esterday's weather cannot be reportedbut it is noted down as an unchanging fact by the meteorologists for their statistics. Likewise, last week's football matches normally cannot be shown this week again. Information is not "mopped-up" either. Once it is uttered it becomes hi-story, i.e., the part of a story that has been told. Next week's football results do neither prove nor disprove this week's, they just continue the story. Unlike scientific facts, the information produced in the mass media is in constant need of renewal. This strange mechanism that transforms information into non-information by its very utterance results in a remarkable acceleration of time. We need new information on a steady basis. Once we have heard today's news, we need to hear tomorrow's as well to follow the story. The same is the case with entertainment and sports programmes. The process of knowing our world is thus considerably sped up. Or, as Niklas Luhmann puts it: "fresh money and new information are two central motives of modern social dynamics." 4

In pre-mass media societies one could know the world by getting an education. This is no longer the case in the times of the mass media. The education system certainly provides us, for instance, with scientific knowledge that enables us to pursue a career, but in order to be aware of what goes on in society on a daily basis we rely on the mass media as our source of information. The education system provides us, among other things, with facts, but not with information in the specific sense outlined above. In contemporary society, the mass media have established a monopole on the production of knowledge as information. We rely on the mass media to follow the stories that constitute the context of our life: the political stories and the war stories in the news, the stories of the films and the soap operas that everybody talks about, the unfolding of fashions and continuously new products that the advertisements familiarize us with, etc.

The "social dynamics" that is fuelled by the mass media is a dynamics of knowledge, a "virtual" dynamics, so to speak. Instead of relatively stable paradigms that we can settle in, the mass media make us part of an ongoing story that is in continuous need of being continued-and it is us who continue it. We are not only passive observers of the story, it is our story that is told, and the mass media are ours too, we are inside and outside at the same time.

${ }^{4}$ Niklas Luhmann, T he Reality of the Mass M edia, 21. 
H. MOELLER 9

We take part in the elections that the media report on, we see our presidents in the news, the advertisements show us the beers we drink and the clothes we wear, the entertainment programmes are the products of our fancies, and we see the stars that we identify with etc. By observing the mass media and by taking in their information we do not merely watch a spectacle and a narrative, the spectacles and the narratives are our own. The knowledge they produce is our own knowledge and we take part in the temporality of their structure; their speed is ours.

IV

In the light of these developments in a mass media society, Aristotle's dictum takes on a new significance: "All men by nature desire to know." Once again, we can focus on the desirethat Aristotle talks about. We all have a desire to know - to know the new film with our favorite actor, the new news with the latest coverage of the development of the political scandal, etc. And we have to have this desire because otherwise we lose contact with our reality, with the story of which we are an intrinsic part. The desire for information becomes as socially essential as the intake of new food is biologically essential. In this sense, the desire for knowledge has truly become our nature In an ironical sense, the mass media have turned us into passionate knowledge pursuers. $\mathrm{O}$ ur desire for knowledge is, on principle, insatiable. If information turns into non-information once it is uttered, our desire of knowledge can never be completely fulfilled. There is always a new sequel that we haven't yet seen. The story- and it is our story- must go on.

Apologists of the new media praise this new kind of knowledge and in their view the desire for it is noble, as for Aristotle it is what dignifies us as truly human. Through the mass media, and particularly through the new media such as the Internet, society makes us all part of the production of knowledge. We are not only passive observers. The news are news about our governments, the elections are those we take part in, the products are the products we purchase- they are displayed for our consumption. The mass media are the medium for the autopoietic self-reproduction of our knowledge. The information is for, by, and about us humans. What a great "democratic" achievement- the production of knowledge has finally become common! And it needs our attention every day. In the daily renewal of information we don't merely sit at the sidelines, it is we who make the news and the shows. Instead of being an "objective" realm of facts disconnected from our daily life, information has become our life and the desire for it is once more our human nature.

Under these circumstances, however, some may also ascribe new significance to the Daoist position on knowledge. An insatiable desire for knowledge may well be conceived of as a dilemma. O nce we establish the code information/non-information we are trapped in a hamster's wheel. The movement of information is entirely ours- but it does not get us anywhere. Knowledge becomes all-pervasive and meaningless at the same time. 


\section{KNOWLEDGE AS ADDICTION}

Seen from a Daoist perspective, the code information/noninformation establishes a communicational craving that makes it impossible to arrive at a point of rest. Contemporary mass media society illustrates the Daoist point quite well: The production of knowledge results in a cycle of addiction. The more information we get, the more we need; the more knowledge we have, the more we lack. In a situation like this, a D aoist would suggest a minimization of knowledge and the quelling of the desire for information. Instead, one would aspire to arrive at a state of knowing or mastering non-knowledge. The difficulty that is obviously involved in such an attempt may at least make the ancient $\mathrm{D}$ aoist paradox that was mentioned above understandable: To master or know non-knowledge is an arduous task that indeed takes great knowing-how and perhaps a sage to achieve.

D epartment of Philosophy, Brock U niversity, Canada

\section{References Cited}

Kuhn, Thomas, The Structure of Scientific R evolutions (Chicago: Chicago University Press, 1962).

Luhmann, Niklas, D ie W issenschaft der G esellschaft (Frankfurt/ Main: Suhrkamp, 1990).

, The Reality of the Mass Media, trans. by Kathleen Cross (Stanford: Stanford University Press, 2000).

Moeller, Hans-Georg ed. and trans., D aodejing (Laozi) (Chicago: O pen Court, 2007). 